\title{
O ESTADO COMO GESTOR DO DESENVOLVIMENTO INDUSTRIAL, TECNOLÓGICO E SOCIAL: O EXEMPLO DE CAMPO LARGO-PR".
}

\author{
Francisco Grabovski Neto ${ }^{1}$ \& Dario E. A. Dergint ${ }^{2}$
}

\section{A TECNOLOGIA COMO FATOR DE ATENDIMENTO ÀS NECESSIDADES SOCIAIS, E COMO A GESTÃO DA TECNOLOGIA PODE AFETAR A COMPETITIVIDADE EMPRESARIAL NO SETOR INDUSTRIAL:}

A história do desenvolvimento econômico mostra que para ocorrer a atividade produtiva em uma determinada economia abrangida por uma região ou país, é necessária a existência de fatores que quando combinados possibilitem a realização da produção de bens e/ou serviços.

Estes fatores são tradicionalmente denominados pelos economistas clássicos e pensadores da história econômica como "Fatores de Produção", e devido a seu grau de importância e utilização foram sendo enumerados e definidos por diversos autores ao longo do tempo.

Em uma visão já mais atualizada, ROSSETTI (1997 p. 189) definiu que os "fatores de produção" são: Terra (Recursos Naturais), Trabalho (Recursos Humanos), Capital (máquinas e Equipamentos), Capacidade Tecnológica e Capacidade Empresarial. Sendo este último fator denominado por muitos autores como agente produtivo. Além disto, cabe ressaltar que todas as relações e interações entre estes diversos fatores destinam-se a produção de bens e serviços, e ocorrem em um sistema produtivo bastante complexo, 0 qual podemos chamá-lo de "Sistema Econômico".

O fator da capacidade tecnológica, com o profundo processo de mudanças estruturais ocorrido nas sociedades desde a Revolução Industrial ocorrida na segunda metade do século XVIII, fez com que este fator estivesse cada vez mais presente na evolução dos processos produtivos industriais, o que propiciou um aumento substancial da produção, ocasionando uma melhoria significativa nos índices de qualidade e produtividade, e que passou a direcionar o pensamento econômico para 0 desenvolvimento econômico.

O entendimento sobre a abrangência do que seja a tecnologia, bem como a sua importância no processo de produção é descrita com muita propriedade através da seguinte citação de BARBIERI (1990 p.153):

"A Tecnologia pode ser entendida como um conjunto de conhecimentos de natureza diversa, aplicados à produção de bens e serviços. Este conjunto envolve tanto aspectos materiais representados pela "maquinaria", quanto as habilidades para produzi-la e acioná-la, bem como as atividades administrativas decorrentes".

A capacidade empresarial esta relacionada com a disponibilidade de recursos financeiros para realização de investimentos, que o agente produtivo deve possuir para combinados com os demais "fatores de produção" obter a produção de bens e serviços

\footnotetext{
${ }^{1}$ Economista com Especialização em Economia de Empresas / Mestrando em Tecnologia (PPGTE). E-mail: fcogneto@terra.com.br

${ }^{2}$ Prof. Dr. do Programa de Pós-Graduação em Tecnologia (PPGTE) - "Mestrado em Tecnologia". E-mail: dergint@ppgte.cefetpr.br
} 
que serão ofertados no mercado consumidor, com a finalidade principal de satisfazer as necessidades dos consumidores integrantes deste mercado.

A interdependência dos fatores de produção e suas interações; bem como, a complexidade de um "Sistema Econômico", além da forma de atuação de seus diversos agentes; quer sejam o governo, as empresas, as famílias (consumidores finais) e as instituições de ensino e pesquisa, os quais certamente ocupam um papel relevante no processo do desenvolvimento econômico, social e tecnológico de uma determinada região. Porém a grande complexidade de suas relações é de difícil abordagem e representação gráfica.

No entanto, para facilitar o entendimento destas relações, é demonstrado na figura no . 01 a seguir, uma representação bastante simplificada de um "Sistema Econômico", seus elementos essenciais como por exemplo os fatores produtivos, o Fluxo Monetário e o Fluxo Real de Bens e Serviços produzidos por uma economia de uma determinada região.

\section{REPRESENTAÇÃO GRÁFICA SIMPLIFICADA DE UM MODELO DE SISTEMA ECONÔMICO:}

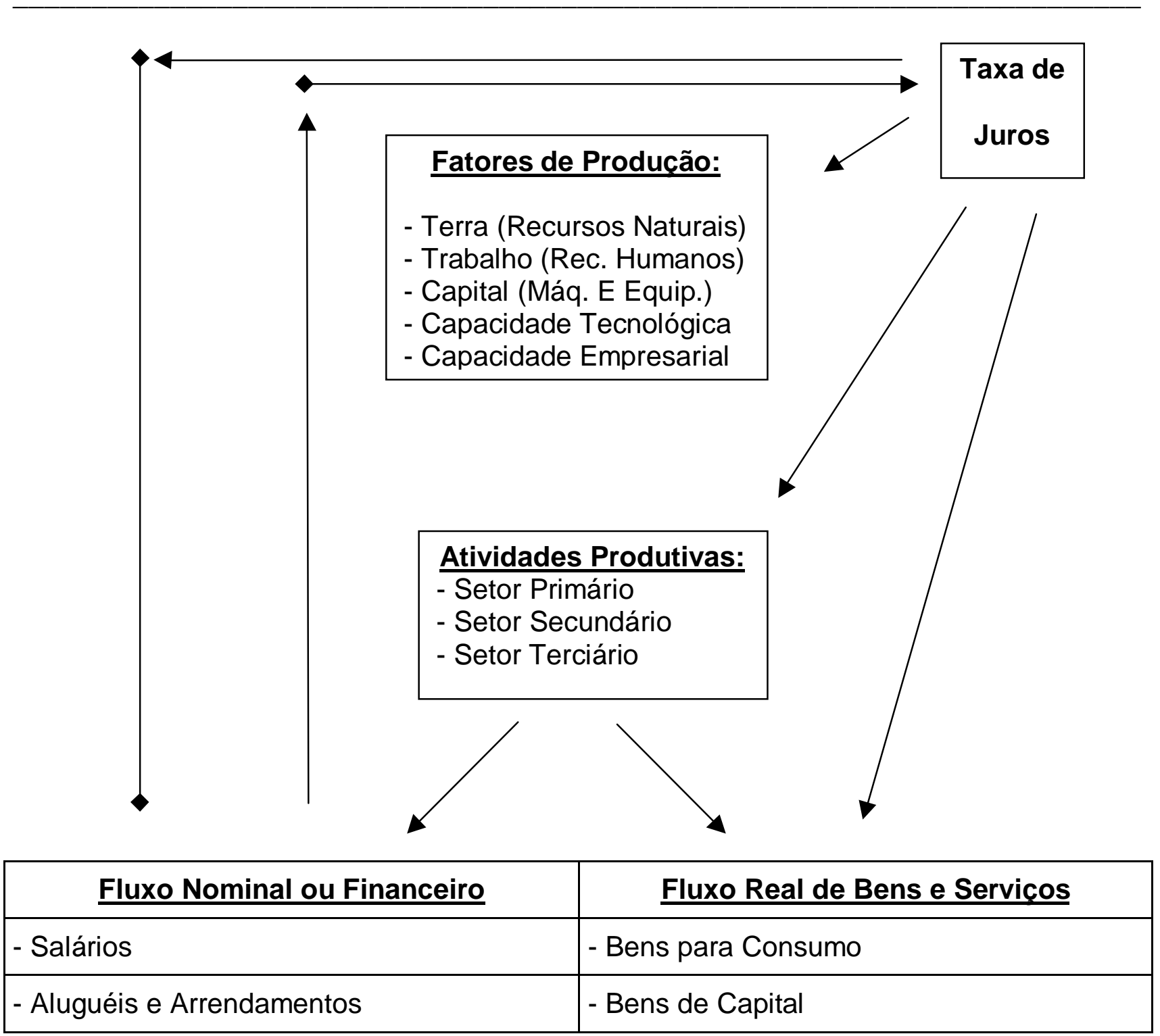


Revista Eletrônica de Ciência Administrativa (RECADM) - ISSN 1677-7387

Faculdade Cenecista de Campo Largo - Coordenação do Curso de Administração

v. 1, n. 1, maio/2003 - http://revistas.facecla.com.br/index.php/recadm/

\begin{tabular}{|l|l|}
\hline - Royalties & - Serviços de Consumo \\
\hline - Lucros e Dividendos & - Serviços para formação de Capital \\
\hline - Juros & \\
\hline
\end{tabular}

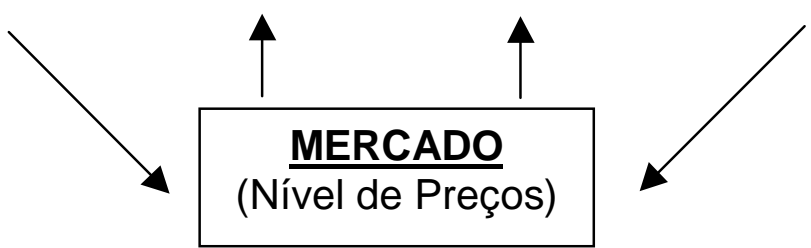

FIGURA № . 01 - Fonte adaptada de: ROSSETTI, José Pascoal - Introdução à Economia. P. 189 17ª . Edição. SÃO PAULO: Editora Atlas, 1997.

Conforme pode ser constatado no modelo demonstrado pela Figura no․ 01 , combinando-se os fatores de produção, obtem-se a produção de bens e serviços, a qual destina-se atender as necessidades do mercado consumidor de uma determinada região.

A capacidade empresarial que a industria possui de utilizar-se de determinada tecnologia para produzir seus produtos e/ou serviços, esta relacionada com o tipo e as características do segmento de mercado em que ela atua; bem como, com 0 comportamento do consumidor final.

No entanto, também o avanço tecnológico realizado através de inovações introduzidas nos processos produtivos e/ou na qualidade dos produtos finais ofertados ao mercado, podem afetar o comportamento do consumidor e/ou ainda gerar novas necessidades sociais.

Qualquer mudança no processo produtivo, que propicie sua evolução quer seja em máquinas e equipamentos, ou ainda mesmo a simples alteração na forma de gestão da produção, e/ou atividades relacionadas que contribuam para a produção de bens e serviços, pode constituir uma alteração tecnológica. Sendo assim, a "inovação tecnológica" pode ocorrer na forma de utilização do processo produtivo, ou ainda em qualquer etapa da produção de novas tecnologias.

Com o intuito de esclarecer de forma simples o que seja a expressão "inovação tecnológica" podemos utilizar a definição simples e objetiva de SÁBATO (1972 p.3) citado por BARBIERI (1990 p.43), ou seja, "Inovação Tecnológica ou simplesmente inovação é toda a mudança numa dada tecnologia".

SHUMPETER (1939), em sua Teoria do Desenvolvimento Econômico ressalta que as inovações tecnológicas impulsionam a formação dos ciclos econômicos. Porém, 0 mesmo autor afirma que para as inovações tecnológicas se processarem elas deverão ser oportunas; ou seja, serem viáveis economicamente para que os empresários ao implementarem estas inovações tecnológicas na produção de bens e/ou serviços possam remunerar os recursos financeiros investidos no emprego da nova tecnologia, auferindo assim lucros.

A capacidade empresarial para investimentos em novas tecnologias, em economias não desenvolvidas é prejudicada pela escassez de recursos financeiros 
Revista Eletrônica de Ciência Administrativa (RECADM) - ISSN 1677-7387

Faculdade Cenecista de Campo Largo - Coordenação do Curso de Administração

v. 1, n. 1, maio/2003 - http://revistas.facecla.com.br/index.php/recadm/

disponíveis para investimentos em Pesquisa \& Desenvolvimento de novas Tecnologias, o que sem dúvida afeta a competitividade de uma região industrial localizada em economias não desenvolvidas.

Para poder equacionar a problemática da escassez de recursos financeiros para investimentos em projetos tecnológicos nestas regiões, temos que analisar alguns modelos de "Sistemas de Inovação", além de abordarmos alguns instrumentos de políticas de Desenvolvimento Tecnológico.

Segundo o Modelo de PINCH \& BIJKER (1987 p.23) o processo de inovação tecnológica ocorre de forma linear, partindo da "pesquisa básica" até chegar ao "Uso" pelo consumidor final, conforme demonstra a figura $\mathrm{n}^{\circ}$. 02, a seguir:

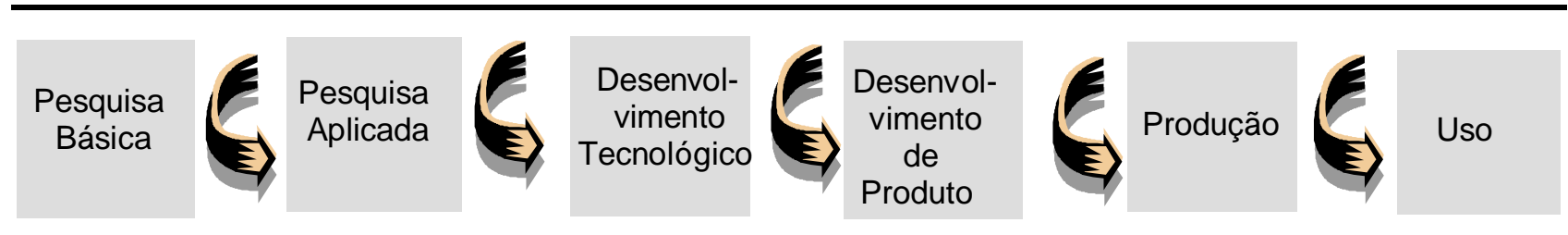

\section{FIGURA № .02 - Modelo de PINCH \& BIJKER}

No entanto, SCHUMPETER (1939) classificou o processo de inovação tecnológica, em três fases distintas, conforme apresentamos na figura $n^{\circ}$. 03 a seguir:

\section{FASES DO PROCESSO DE INOVAÇÃO TECNOLÓGICA}
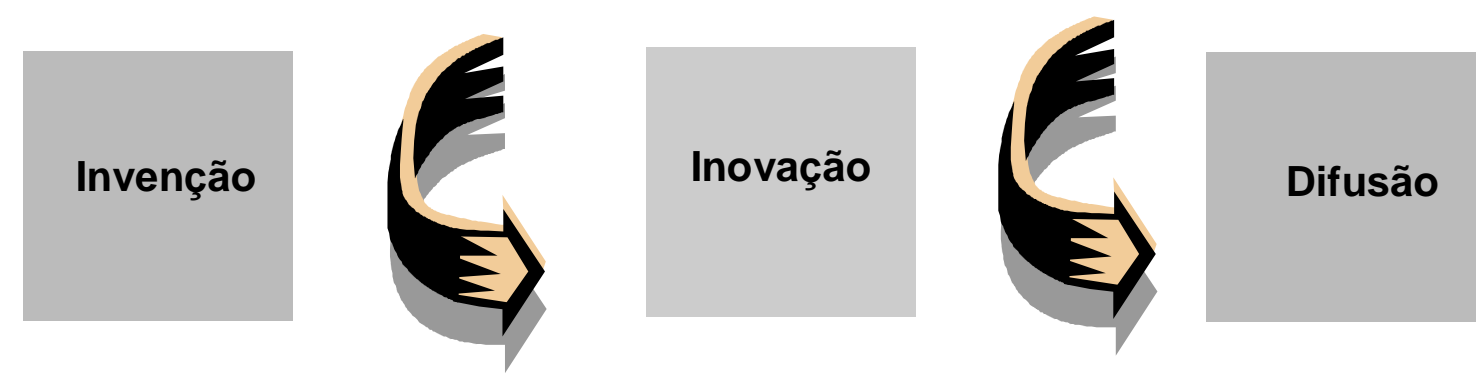

FIGURA № .03 - Fonte Adaptada: SHUMPETER (1939)- Fases do Processo de Inovação Tecnológica

Segundo REIS (2000), estas 3 (três) fases do processo de inovação tecnológica são descritas por SHUMPETER (1939), da seguinte maneira:

- Invenção: ocorre quando é demonstrada a viabilidade de um novo produto e/ou processo.

- Inovacão: ocorre quando a empresa obtém sucesso na venda de um produto novo ou melhorado ou na utilização de um processo novo ou aperfeiçoado. 
- Difusão: é a fase em as inovações são adaptadas em larga escala por outras empresas, ocorrendo um processo denominado "atualização tecnológica".

No entanto, muitos autores e entre eles BARBIERI (1990), consideram que o processo de inovação tecnológica só se completa quando a evolução tecnológica proposta pela invenção quer seja de produto e/ou processo, é efetivamente transformada em produtos e/ou processos, chegando a atingir o mercado consumidor.

Os Modelos lineares do Processo de Inovação, tradicionalmente apresentam um fluxo contínuo, que inicia na pesquisa básica, tornando-se pesquisa aplicada, e até o momento em que seja concluído o processo de inovação, após a efetiva evolução tecnológica transformada em produtos e/ou processos disponíveis ao mercado consumidor.

Como exemplificação de modelos complexos não lineares do processo de inovação tecnológica, mais aplicáveis à realidade das economias não desenvolvidas, destaca-se o modelo proposto por KLINE AND ROSENBERG (1986), também conhecido como 'Modelo das Ligações em Cadeia"ou "CHAIN-LINK MODEL", conforme demonstrado na Figura no . 04 à seguir:

MODELO DE LIGAÇÕES EM CADEIA - (KLINE and ROSENBERG):

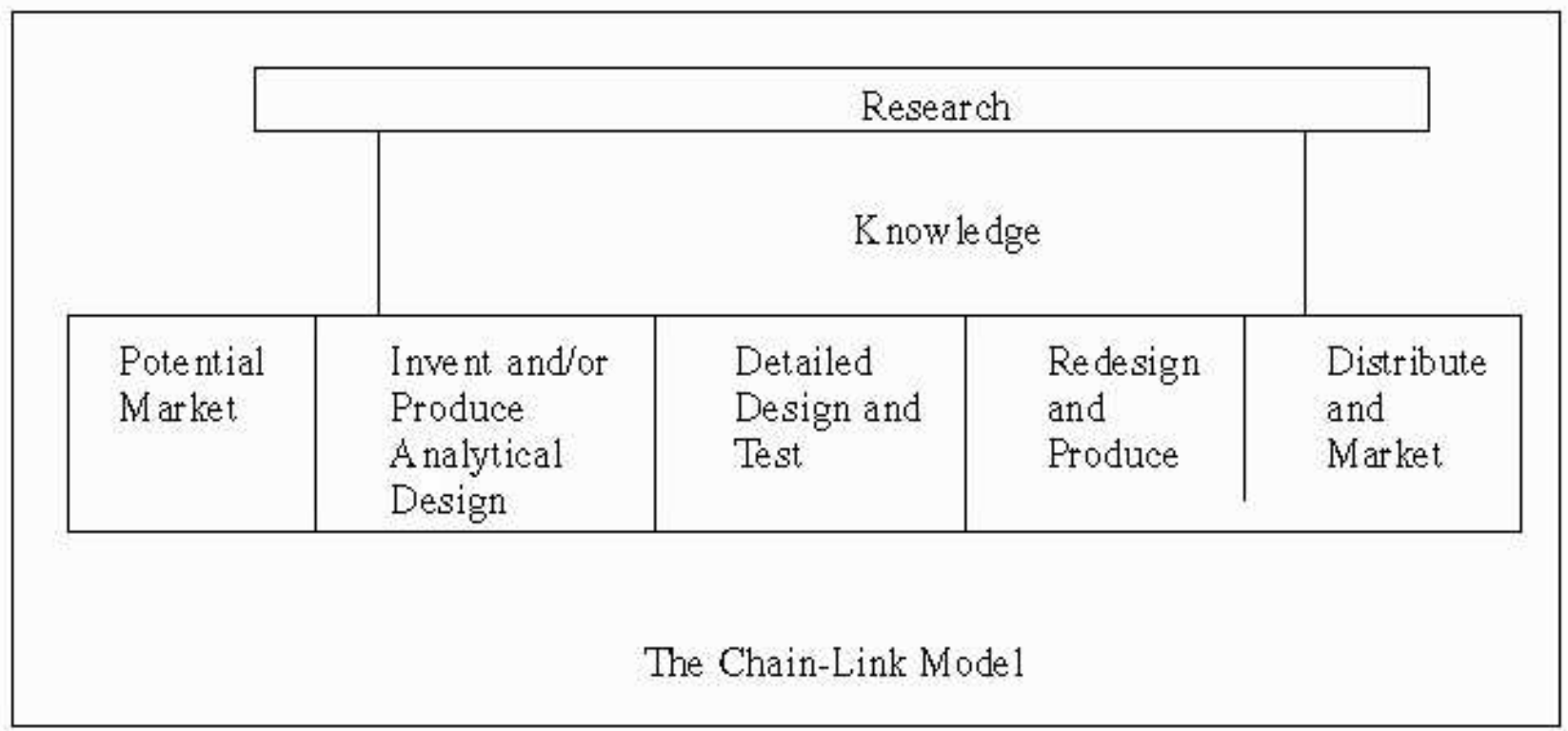

FIGURA № 04 - Fonte: KLINE and ROSENBERG (1986)

A figura $\mathrm{n}^{\circ}$. 04 - mostra que o modelo proposto possui as atividades inovadoras, elementos de pesquisa, mercado e o conhecimento como elementos fundamentais.

O grande diferencial deste modelo em relação aos "modelos Lineares" é que tradicionalmente o conhecimento é descrito como um fluxo contínuo, através das diversas etapas do processo de inovação tecnológica. No entanto, no modelo proposto o 
conhecimento pode-se relacionar ou até mesmo surgir em diferentes etapas do processo de inovação, podendo realimentar-se ciclicamente, conforme expressa a representação gráfica.

A seqüência linear do conhecimento no fluxo do "processo de inovação" partindo tradicionalmente da pesquisa básica para o mercado consumidor, segundo REIS (2000) foi estuda por LANGRISH et al, apud RUIVO (1997) e denominada "Discovery-push" ou ainda "Science-push"; ou seja, o desenvolvimento tecnológico ocorre na visão tradicionalista tendo sua origem na invenção.

No entanto, os mesmos autores relatam também que a inovação pode surgir através da demanda pelo mercado; ou seja, a inovação é estimulada pelo próprio mercado conforme demonstra o modelo "Market-pull" ou "Demand-pull", o que pode ser mais bem explicado através de modelos não lineares.

Nas economias em desenvolvimento como o Brasil, a problemática da escassez de Recursos financeiros para investimentos em Pesquisa \& Desenvolvimento por parte do Setor privado torna o "Sistema do Processo de Inovação" ainda mais complexo, o que dificulta qualquer representação gráfica, porém para facilitar o entendimento esboçaremos uma representação gráfica bastante simplificada, conforme demonstra a figura $\mathrm{n}^{\circ} 05$ a seguir:

\section{ESBOÇO DAS RELAÇÕES E DOS AGENTES PREFERENCIAIS ENTRE AS ETAPAS} DO PROCESSO DE INOVAÇÃO TECNOLÓGICA NO BRASIL EM 2002:

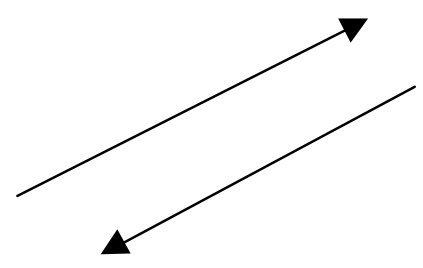

\section{Conhecimento \\ Científico \\ Tecnológico}
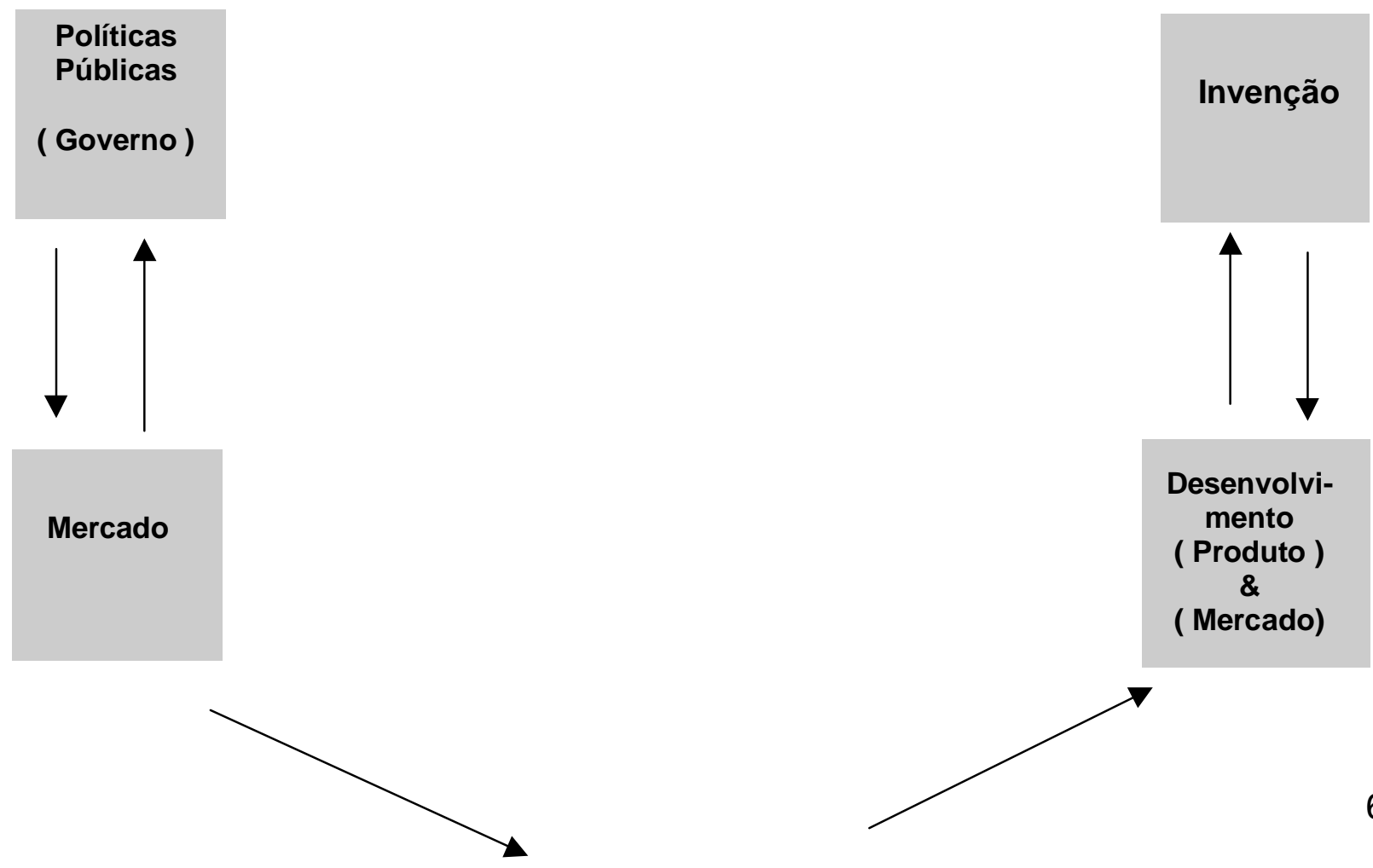
Revista Eletrônica de Ciência Administrativa (RECADM) - ISSN 1677-7387

Faculdade Cenecista de Campo Largo - Coordenação do Curso de Administração

v. 1, n. 1, maio/2003 - http://revistas.facecla.com.br/index.php/recadm/

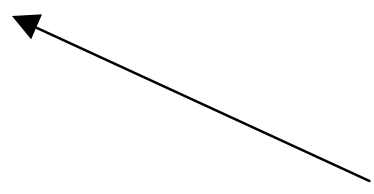

Produção Industrial

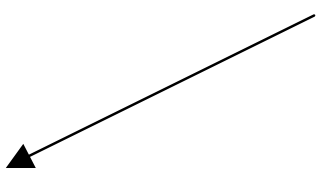

( em escala )

FIGURA № . 05 - Representação Gráfica criada pelo autor baseada em REIS (2000).

$\mathrm{Na}$ figura no 05 estão representadas apenas as relações preferenciais de um possível "Modelo de um Sistema Complexo de Inovação Tecnológica", pois ainda existem inter-relações de menor incidência entre as diversas etapas descritas, as quais atuam e afetam o Sistema como um todo.

Como por exemplo, o desenvolvimento de novos produtos e/ou processos industriais pode sofrer influência de tecnologias já existentes pelo setor industrial. Outro exemplo é o fato das políticas públicas poderem influenciar o desenvolvimento de pesquisa pura e/ou aplicada, e também elas podem afetar o mercado, que poderá afetar a produção industrial.

Sob a ótica da competitividade atual no setor industrial, as empresas têm como objetivo principal à satisfação das necessidades de seus clientes. Para atender este objetivo elas têm procurado melhorar a qualidade de seus produtos e processos produtivos.

A questão da busca da satisfação do cliente através da melhoria da qualidade dos produtos e processos produtivos para ampliação da participação no mercado (Market Share) foi abordada por DEMINNG (1989), sendo atualmente muito utilizadas pelas empresas no ramo industrial e de serviços através do T.Q.C. "TOTAL QUALITY CONTROL" conhecido no Brasil como Controle de Qualidade Total.

No caso, da produção industrial, é efetuado um controle da qualidade das peças e/ou produtos fabricados; a fim de reduzir e/ou eliminar perdas e propiciar a melhoria da qualidade dos produtos e serviços oferecidos ao mercado consumidor.

Pode-se relacionar a "inovação tecnológica" com a necessidade de satisfação do cliente através da denominada "Reação em Cadeia" citada por DEMINNG (1990 p.2), conforme demonstramos de forma adaptada a seguir:
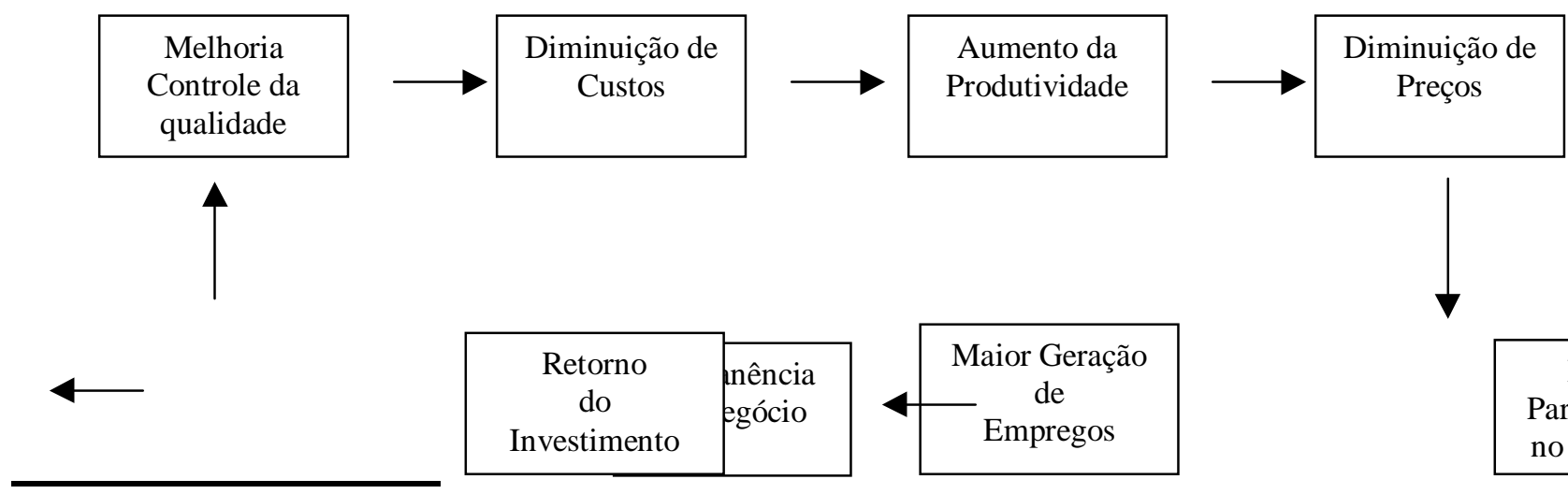
FIGURA № . 06 - Fonte adaptada da "Reação em Cadeia" de DEMINNG (1990 p.2)

Portanto, a tecnologia tem sido um fator determinante para o atendimento das necessidades sociais. As industrias por sua vez motivadas geralmente pelo modelo "market-pull" tem tido a necessidade de promover inovações tecnológicas para melhorar a qualidade de seus produtos e manterem-se competitivas em seus segmentos de mercado.

Em termos de competitividade empresarial, a empresa pode utilizar-se de inovações tecnológicas para ampliar o ciclo de vida de seus produtos. Podendo melhorar a qualidade para obter uma maior satisfação de seus clientes, e com isto obter uma ampliação de sua participação no mercado (Market Share); ou ainda, obter uma otimização de seus custos oriundos da evolução tecnológica de seus processos produtivos, o que também poderá resultar numa prorrogação do ciclo de vida do produto em uma nova segmentação de mercado.

Segundo CLEMENTE (1998 p. 80), "a implicação do conceito de ciclo de vida dos produtos para a elaboração de projetos é imediata e torna necessária considerar a fase em que encontra-se o produto, a duração da fase atual e as subseqüentes, bem como as possibilidades de mudanças devido ao projeto ou aos concorrentes".

Nas economias em desenvolvimento, com a problemática da escassez de recursos financeiros para investimentos, nem sempre o processo de Inovação Tecnológica, ocorre de forma linear como demonstrado nestes modelos. Como geralmente o setor privado destas economias não dispõe de recursos financeiros suficientes para investimentos em projetos tecnológicos, cabe ao governo como gestor do Sistema de Inovação também estimular a capacidade tecnológica das empresas, e uma destas maneiras é a facilidade de financiamento de longo prazo disponibilizada ao mercado de uma determinada região através da estrutura disponível dos "Bancos Regionais de Desenvolvimento".

\section{PORQUÊ O SETOR INDUSTRIAL NECESSITA DE FINANCIAMENTO ESTATAL PARA O DESENVOLVIMENTO TECNOLÓGICO REGIONAL E MELHORIA DE SEUS PROCESSOS PRODUTIVOS:}

Conforme demonstrado anteriormente o financiamento estatal de longo prazo através dos Bancos de Desenvolvimento, é uma forma do Estado regular a economia de uma região.

Além disto, o problema da escassez de recursos para investimentos em projetos tecnológicos (onde o prazo de maturação dos investimentos é geralmente muito longo), além da insuficiência dos recursos da iniciativa privada para realização de inovações tecnológicas, segundo KEYNES (1985) cabe ao governo financiar parte destes empreendimentos, a fim de satisfazer o interesse social.

Conforme SHUMPETER (1939) identifica-se historicamente na economia a necessidade que o empresário possui da obtenção do lucro na realização do processo produtivo, porém o processo de produção apesar de visar o lucro capitalista, propicia a satisfação das necessidades sociais.

Entretanto, na visão empresarial o endividamento causado pela obtenção de empréstimos e financiamentos, pode ser ao mesmo tempo um bom e/ou um mau negócio. 
Será um bom negócio se a empresa obtém um rendimento maior sobre os empréstimos do que os custos destes. Será um mau negócio, em caso contrário, porque as taxas de juros devem ser pagas em datas pré-fixadas, havendo ou não lucro. Segundo a visão abordada por FLEURIET (1980) e BRASIL (1991).

Segundo FLEURIET (1980 p.161) "O Efeito do endividamento sobre os lucros do exercício é freqüentemente chamado de efeito de alavancagem, para evocar o aumento dos lucros (ou de perdas) que ele produz".

Relata MATARAZZO (1991 p.31) "[... que a análise da alavancagem financeira é recomendável nas decisões de financiamentos à longo prazo por comparar o custo das diferentes alternativas de capitais de terceiros com o custo de capital próprio das empresas".

No entanto, a ação de realizar um planejamento financeiro de longo prazo, é de fundamental importância para a gestão da tecnologia do processo produtivo, pois o crescimento e a expansão da empresa no mercado na qual ela está inserida, depende da melhoria da qualidade e produtividade da atividade empresarial; bem como; do desenvolvimento de novos produtos.

Segundo ANSOFT, citado por FLEURIET (1980 p.177) "São os objetivos à longo prazo da empresa que Ihe permitem desenvolver ou manter uma posição frente a seus concorrentes [...]".

O financiamento de longo prazo possibilita tempo suficiente para as empresas atingirem a realização da geração de resultado, capaz de suprir as empresas em sua capacidade de pagamento destes financiamentos conforme a visão de FLEURIET (1980).

Salienta-se que em muitos projetos de empreendimentos caso não haja financiamentos de longo prazo, com períodos de carência para pagamento do valor principal (valor original do empréstimo atualizado monetariamente) e taxas de juros inferiores aos oferecidos pelo mercado em geral, muitos investimentos de longo prazo em empresas deixarão de serem realizados; o que faz com que empresas localizadas em uma determinada região sejam prejudicadas em comparação com outras situadas em uma região beneficiada por crédito de longo prazo.

Embora, os recursos financeiros sejam imprescindíveis para a realização de investimentos por parte das empresas do setor industrial; ou seja, tanto para realizar a inovação tecnológica nos processos produtivos industriais, e/ou para a atualização tecnológica (aquisição de tecnologia já existente), são necessários recursos financeiros.

No caso de haver insuficiência de recursos financeiros para investimentos por parte da iniciativa privada, caberá ao Estado o papel de criar mecanismos de estímulo a estas atividades para obtenção de uma situação de pleno emprego dos fatores de produção conforme relata a teoria Keynesiana.

Além disto, para propiciar o desenvolvimento industrial de uma região cabe considerar o fato, da atração de novas industrias com grande tecnologia em seus processos produtivos, que para implantação em uma localidade deverão encontrar abundância dos fatores de produção.

A implantação de novas unidades fabril, geralmente implica em elevados custos de implantação e geralmente necessitam como estímulo "financiamentos de longo prazo" para sua implantação, a fim de possibilitar tempo suficiente para que seja possível obter 
um retorno satisfatório sobre os investimentos em seus ativos (bens e direitos conforme lei 6404/76). Estes investimentos possibilitam a geração de empregos e renda, necessários para satisfazer as necessidades sociais de uma região.

Conforme PORTER (1991 p.314) Uma análise apropriada da entrada de uma indústria em um novo mercado de uma região, [...] "deverá levar em conta os seguintes custos e benefícios":

1. Os custos dos investimentos requeridos para operar no novo negócio, tais como investimentos em instalações fabris e em estoques (alguns dos quais poderão ser aumentados devidos á barreiras e entrada estruturais);

2. Os investimentos adicionais requeridos para superar outras barreiras estruturais, tais como identificação de marca e tecnologia patenteada;

3. O custo esperado da retaliação por parte dos participantes da indústria contra a entrada, comparada com;

4. Os fluxos de caixa esperados por estar na indústria".

Face ao relato acima, ressaltamos que todos os custos de implantação de uma nova indústria, que conforme MARTINS (1998) poderão ser consideradas como despesas diferidas ou ainda despesas pré-operacionais, constituirão de desembolsos do investimento inicial, que somente serão absorvidas durante o período de atividade.

Portanto, nessas condições podemos considerar estratégica a preferência das industrias pela utilização de financiamento de longo prazo, no caso de seus recursos próprios serem insuficientes para realizar a totalidade dos investimentos em inovação e/ou atualização tecnológica, a fim de não comprometerem o seu capital de giro.

\section{O PAPEL DO ESTADO COMO GESTOR DO DESENVOLVIMENTO INDUSTRIAL TECNOLÓGICO E SOCIAL DE UMA REGIÃO: O EXEMPLO DE CAMPO LARGO/PR:}

As políticas de uma cidade estão inter-relacionadas com políticas regionais e nacionais, confirmando que as limitações de uma cidade, por ela própria, em apresentar resultados efetivos quanto à sua sustentabilidade, são limitados também por questões políticas e administrativas.

O que produzir, como produzir, para quem produzir, tornam-se questões-chaves que devem fazer parte de todo processo de gestação de projetos tecnológicos e econômicos. Deixa-se um ambiente gerido pelo conceito estreito de "desenvolvimento econômico" para partir para a exploração do conceito mais amplo de "desenvolvimento sustentável".

Conforme relato do Prof. Dr. (CEFET/PR) Eloy Fassi Casagrande Jr. em 13/06/2001, "podemos definir Desenvolvimento Sustentável como um norteador de ações sistêmicas que possam garantir qualidade de vida as atuais e futuras gerações, através de um processo de transformação do atual modelo de crescimento econômico. Este processo deve integrar a exploração racional dos recursos naturais a um modelo de desenvolvimento tecnológico ambientalmente saudável, a orientação ética dos investimentos a melhoria na distribuição de renda e, ainda, priorizar a alfabetização ecológica e a democratização da cultura“. 
Portanto, no caso específico de Campo Largo, apenas uma ação isolada da Prefeitura local seria insuficiente para atingir o "Desenvolvimento Sustentável", portanto torna-se imprescindível uma atuação conjunta das esferas Estadual e Federal, no tocante a políticas de Desenvolvimento, criando um cenário propício para atração de investimentos, e realizando o papel de normalização para a Gestão da Tecnologia.

O grande desafio de cidades como Campo Largo, ao longo do século XXI, será o de promover a satisfação das necessidades sociais da comunidade local, integrando as relações econômicas e sociais com a exploração não predatória dos recursos naturais de forma harmônica, tornando possível a utilização mais adequada do uso da tecnologia, em favor da garantia da qualidade de vida atual e futura da comunidade local.

Conforme (KEYNES) em sua Teoria do Emprego, do Juro e da Moeda, o Estado deverá estimular a atividade econômica para que a economia possa atingir o estágio de Pleno Emprego dos Fatores de Produção; ou seja, no caso de Campo Largo, são necessários investimentos governamentais (municipais, estadual e federal) em infraestrutura, para que se possa implantar um pólo de desenvolvimento auto-sustentável nesta região.

Primeiramente uma região em que pretende tornar-se um pólo de desenvolvimento, como a exemplo da região de Campo Largo, deve se preocupar em implantar centros de pesquisa aplicada em parceria com Institutos de Pesquisa ou Universidades, que busquem explorar a diversidade existente tanto agrícola, quanto industrial da região. Esta ação resultaria na formação de recursos humanos, estruturação de laboratórios, incubação de empresas, convênios e acordos com instituições de ciência e tecnologia locais e regionais, nacionais e internacionais para a criação de um "Parque Tecnológico" que tivesse como objetivo principal explorar os recursos naturais de forma harmônica e não predatória; isto é, sem comprometer a qualidade de vida da população da região a ser explorada.

Considerando que a região de Campo Largo já possui uma relativa infra-estrutura, beneficiando-se tanto da proximidade da capital do estado quanto de uma riqueza abundante de seus recursos naturais (como pôr exemplo as características do solo argiloso adequado à industria cerâmica), e o governo estadual tem demonstrado através da atuação, da S.E.I.T.(Secretária de Estado da Indústria, do Comércio e do Turismo), uma participação ativa no aspecto atração de novos investimentos para implantação de industrias ao longo de todo o Estado do Paraná.

O município de Campo Largo poderá utilizar-se de uma ação conjunta e integrada com o governo estadual para promover o Desenvolvimento Tecnológico, Econômico e Social, a exemplo dos diversos municípios aonde ocorreu à implantação/ampliação da atividade industrial, conforme demonstra a tabela a seguir:

TABELA 1 - INVESTIMENTOS PRIVADOS NO PARANÁ - 1995 À 2001 - OS 15 MAIORES SETORES DE ATIVIDADES ( em milhares de R $\$$ )

\begin{tabular}{|l|l|l|r|r|}
\hline Nome da Industria & $\begin{array}{l}\text { Ramo de } \\
\text { Atividade }\end{array}$ & Cidade & $\begin{array}{c}\text { Valores } \\
\text { (milhares } \\
\mathbf{R} \$ \text { ) }\end{array}$ & $\begin{array}{c}\text { Empregos } \\
\text { gerados }\end{array}$ \\
\hline Renault & Montadora & $\begin{array}{l}\text { S. J. dos } \\
\text { Pinhais }\end{array}$ & 1.382 .055 & 2.500 \\
\hline
\end{tabular}


Revista Eletrônica de Ciência Administrativa (RECADM) - ISSN 1677-7387

Faculdade Cenecista de Campo Largo - Coordenação do Curso de Administração v. 1, n. 1, maio/2003 - http://revistas.facecla.com.br/index.php/recadm/

\begin{tabular}{|c|c|c|c|c|}
\hline Volks/Audi & Montadora & $\begin{array}{l}\text { S.J. dos } \\
\text { Pinhais }\end{array}$ & 750.000 & 3.000 \\
\hline $\begin{array}{l}\text { Usina Termoeléctrica Araucária } \\
\text { - UEG }\end{array}$ & $\begin{array}{l}\text { Termoeletricidad } \\
\text { e }\end{array}$ & Araucária & 550.000 & 60 \\
\hline Tafisa Brasil & $\begin{array}{l}\text { Manufaturas } \\
\text { MDF }\end{array}$ & Piên & 440.000 & 375 \\
\hline Volvo do Brasil Veículos Ltda & Montadora & Curitiba & 394.560 & 600 \\
\hline $\begin{array}{l}\text { CSN - IMSA - Aços Revestidos } \\
\text { S.A }\end{array}$ & $\begin{array}{l}\text { Chapas aço } \\
\text { laminadas }\end{array}$ & Araucária & 390.000 & 500 \\
\hline $\begin{array}{l}\text { Global Village Telecom Ltda - } \\
\text { GVT }\end{array}$ & Telefonia & Maringá & 300.000 & 500 \\
\hline Masisa do Brasil Ltda & MDF-OSB-PB & $\begin{array}{l}\text { Ponta } \\
\text { Grossa } \\
\end{array}$ & 249.000 & 200 \\
\hline Placas do Paraná S/A & $\begin{array}{l}\text { MDF/Aglomerad } \\
\text { o }\end{array}$ & Jaguariaiva & 237.000 & 200 \\
\hline Kraft Lacta Suchard Brasil S/A & $\begin{array}{l}\text { Chocolates e } \\
\text { outros }\end{array}$ & Curitiba & 210.000 & 2.200 \\
\hline $\begin{array}{l}\text { Klabin S/A - Fabricadora de } \\
\text { Papel e Celulose S/A }\end{array}$ & Papel e Celulose & $\begin{array}{l}\text { Telêmaco } \\
\text { Borba }\end{array}$ & 206.000 & 300 \\
\hline Cervejarias Kaiser Brasil Ltda & Bebidas & $\begin{array}{l}\text { Ponta } \\
\text { Grossa }\end{array}$ & 150.000 & 300 \\
\hline Tetra Pak Ltda & Emb. Especiais & $\begin{array}{l}\text { Ponta } \\
\text { Grossa }\end{array}$ & 100.000 & 1.000 \\
\hline Itap Bemis Ltda & Plásticos & Londrina & 83.000 & 600 \\
\hline $\begin{array}{l}\text { Continental do Brasil Produtos } \\
\text { Automotivos Ltda }\end{array}$ & Pneus & $\begin{array}{l}\text { Ponta } \\
\text { Grossa }\end{array}$ & 80.000 & 300 \\
\hline Sadia & \begin{tabular}{|l} 
Aves \\
Congeladas e \\
Alimentos \\
Congelados
\end{tabular} & $\begin{array}{l}\text { Paranaguá, } \\
\text { Fco Beltrão, } \\
\text { DoisVizinhos } \\
\text {, Toledo e } \\
\text { P. Grossa }\end{array}$ & 115.995 & 1.012 \\
\hline \begin{tabular}{|l} 
Total 15 maiores \\
Privados no PR. >
\end{tabular} & vestimentos & & 5.637 .610 & 13.647 \\
\hline
\end{tabular}

Fonte: adaptada SEIT/PR. (Secretária de Estado da Indústria, do Comércio e do Turismo do PR.)

Embora, existam inúmeros programas estaduais promovidos pela SEIT, os quais visam melhorar as condições de infra-estrutura para atração de investimentos, tendo (conforme demonstrado pela tabela acima) apresentado bons resultados para a atração de investimentos para implantação de industrias dos mais diversos setores econômicos em diversas regiões do Paraná; caberá ao município uma integração de seu plano de governo aos programas já existentes.

O município de Campo Largo poderá realizar uma ação conjunta com o governo estadual através da utilização dos diversos Programas, mas deverá a administração local elaborar um Planejamento de ações para reduzir o impacto ambiental e controlar a 
exploração predatória dos Recursos Naturais, pois somente assim poderá propiciar a melhoria das condições de vida de sua população local.

Contrariando a visão de Adam SMITH (1789), em sua consagra obra "A Riqueza Das Nações" que trata a questão dos recursos naturais apenas como fatores geradores de renda, sendo abordados nesta consagrada obra como a "renda da terra"; no entanto, esta contradição ao pensamento clássico econômico é facilmente observada pela existência atual de problemas relacionados com a "escassez dos Recursos Naturais" e sua correlação com a qualidade de vida das populações.

Esta escassez dos Recursos Naturais, bem como a importância da correta utilização destes recursos para evitar a exaustão, e propiciar entre outros aspectos a sustentabilidade do Desenvolvimento foi abordada com muita propriedade pelo casal MEADOWS (1978) no tocante aos "Limites do Crescimento". Portanto, cabe ao Governo (Municipal, Estadual e Federal) não só atrair investimentos financeiros, mas exercer o papel de Gestor da Economia, garantindo a proteção e conservação dos Recursos Naturais, bem como estabelecer regras para a renovação e exploração não predatórias destes bens públicos e, porque não dizer, essenciais a continuidade da vida das espécies e do equilíbrio dos ecossistemas existentes no planeta.

Portanto, embora SHUMPETER (1939) tenha descrito com muita propriedade que a existência do "Lucro Empresarial" seja um elemento essencial para o desenvolvimento econômico de uma região, caberá ao governo a fiscalização da utilização do bem público, a fim de promover não só a geração de empregos e aumento de renda, mas à manutenção das condições ambientais, sendo estas também são essenciais para a "qualidade de vida" de uma população.

\subsection{Quais as ações já definidas pelo Estado do Paraná ?}

O governo do Estado do Paraná tem realizado uma ação conjunta com diversos municípios para possibilitar a atração de investimentos e inseri-los dentro do conceito de desenvolvimento sustentável. Conforme informações obtidas através do site www.pr.gov.br/seit/programas.html, destacamos os seguintes programas:

- Programa de Atração de Investimentos;

- Programa Contribusiness Paraná;

- Programa de Distritos Industriais;

- Programa Especial de Exportações (PEE);

- Programas Feiras e Exposições Internacionais;

- Programa Investe Brasil;

- Programa Paraná Agroindustrial;

- Programa Paraná da Qualidade e Produtividade (Excelência Paraná);

- Programa Rede de Agentes;

Além disto, conforme tabela de Investimentos Privados no PR - no período 1995 à 2001 (disponível no site www.pr.gov.br/seit/programas.html em 31/07/2001), foram realizados aproximadamente $R \$ 5.637 .610 .000,00$ de investimentos privados nos 15 maiores setores de atividades do Estado, gerando aproximadamente 13.647 empregos diretos.

Destaca-se que, para a viabilização destes investimentos, o Paraná utilizou um Programa denominado "Paraná mais Empregos", sendo que o programa propicia em alguns casos a "dilação no prazo de pagamento do I.C.M.S. (Imposto sobre a circulação 
de Mercadorias e Serviços), por um período de aproximadamente 48 meses", com o pagamento parcelado destes impostos.

Logo ao analisarmos o Programa, concluímos que não existe isenção e sim dilação, ou seja, a dilatação do prazo para pagamento do imposto Estadual I.C.M.S.. Considerando o volume de investimentos realizados por empresas privadas no Estado do Paraná no período citado, além de proporcionar um elevado número de empregos gerados com a ampliação da atividade econômica.

Este programa combinado com incentivos fiscais relacionados aos impostos municipais I.P.T.U. (Imposto Predial Territorial e Urbano) e I.S.S. (Imposto sobre Serviços), e ações municipais como doação de terrenos, lograram êxito por todo o Estado, o que inclusive contribuiu para a atração da montadora Chrysler em Campo Largo. No entanto, talvez o ponto mais vulnerável ainda seja a questão do impacto ambiental, o que poderá afetar a sustentabilidade futura do desenvolvimento da região.

Nota: 0 "Programa Paraná mais Empregos" foi suspenso devido a ação direta de inconstitucionalidade promovida pelo estado de São Paulo. Em substituição a esse programa, o governo estadual criou recentemente o PRODEF (Programa para o Desenvolvimento Econômico, Tecnológico e Social do Paraná), através do decreto no . 4323 de 29/06/2001.

\subsection{INFORMAÇÕES ECONÔMICAS E FINANCEIRAS DE CAMPO LARGO:}

TABELA № 02 -ESTABELECIMENTOS E EMPREGADOS POR ATIV ECON (RAIS) - 1998

\begin{tabular}{|l|c|c|}
\hline VARIAVEL & ESTABELECIMENTOS & EMPREGADOS \\
\hline EXTRACAO DE MINERAIS & 23 & 308 \\
\hline IND PROD MINERAIS NAO METAL & 58 & 2.739 \\
\hline INDUSTRIA METALURGICA & 25 & 247 \\
\hline INDUSTRIA MECANICA & 3 & 21 \\
\hline IND MAT ELETR E COMUNICACAO & 4 & 768 \\
\hline IND MATERIAIS TRANSPORTE & 4 & 335 \\
\hline IND DA MADEIRA E DO MOBILIARIO & 61 & 557 \\
\hline IND PAPEL,PAPELAO,EDIT,GRAFICA & 18 & 319 \\
\hline IND BORRACHA,FUMO,COUROS,SIMIL & 11 & 60 \\
\hline QUIM,FARM,VETER,PERF,SAB,OUTRO & 13 & 164 \\
\hline IND TEXTIL, VEST, ARTEF TECIDO & 17 & 373 \\
\hline PROD ALIM, BEB E ALC ETILICO & 42 & 686 \\
\hline SERV INDUSTRIAIS DE UTIL PUBLI & 1 & 80 \\
\hline CONSTRUCAO CIVIL & 54 & 395 \\
\hline COMERCIO VAREJISTA & 384 & 1.817 \\
\hline COMERCIO ATACADISTA & 68 & 341 \\
\hline INST CRED, SEGURO, CAPITALIZ & 12 & 133 \\
\hline ADMIN, TEC PROF, AUX ATIV ECON & 79 & 398 \\
\hline TRANSPORTE E COMUNICACOES & 90 & 614 \\
\hline SERV ALOJ, ALIM, RADIO DIF, TV & 90 & 395 \\
\hline SERVICOS MED, ODONTO E VETERIN & 34 & 100 \\
\hline ENSINO & 18 & 218 \\
\hline
\end{tabular}


Revista Eletrônica de Ciência Administrativa (RECADM) - ISSN 1677-7387

Faculdade Cenecista de Campo Largo - Coordenação do Curso de Administração

v. 1, n. 1, maio/2003 - http://revistas.facecla.com.br/index.php/recadm/

\begin{tabular}{|l|c|c|}
\hline ADMIN PUBL DIRETA E INDIRETA & 5 & 1.575 \\
\hline AGRIC, SILV, CRIACAO ANIMAIS & 57 & 271 \\
\hline ATIVIDADE ECONOMICA - TOTAL & $\mathbf{1 1 7 1}$ & $\mathbf{1 2 . 9 1 4}$ \\
\hline
\end{tabular}

FONTE: MTB.

Conforme demonstra a tabela ํㅡ. 02, o município de Campo Largo apresentou em 1998, significativa geração de empregos nos setores da indústria de produtos minerais e não metálicos absorvendo 2739 empregos, alocados em 58 empresas e o comércio varejista absorveu 1817 empregos, distribuídos entre 384 estabelecimentos. A atividade comercial varejista tradicionalmente gera muitos empregos, embora apresente um número reduzido de empregos por estabelecimento.

Destaca-se que a atividade industrial é a que melhor aproveita os recursos naturais locais, e proporcionalmente produz uma maior geração de empregos em relação ao número de estabelecimentos, ou seja, para cada indústria estabelecida nesse setor, houve uma média de 48 empregos gerados, enquanto, no setor do comércio varejista, a média manteve-se em torno de 4,73 empregos.

A distribuição dos empregos na cidade de Campo Largo apresentou em 1998, os seguintes dados:

- setor industrial absorveu 7052 empregos, o que corresponde a $54,61 \%$ do total;

- setor de comércio atacadista/varejista absorveu 2158 empregos, o que equivale a $16,71 \%$;

- setor de serviços absorveu 3704 empregos, o que equivale a $28,68 \%$.

Pode-se destacar ainda, que os empregos gerados no setor de serviços, como por exemplo, transportes, com 614 empregos, estes postos de trabalhos estão relacionados com a atividade industrial. Além disso, tanto o setor de comércio quanto o de serviços, visam satisfazer também as necessidades de consumo da população empregada na atividade industrial.

Sob a ótica da sustentabilidade econômica, através deste levantamento, constatouse a relevante importância do setor industrial como gerador de empregos e renda, uma vez que Campo Largo apresenta recursos naturais abundantes em minerais não metálicos como o calcário, quartzito industrial e a argila, ambos os insumos usados em larga escala na indústria da construção civil e cerâmica.

No entanto, a preocupação com a exaustão dessas riquezas requer uma política de controle de utilização desses recursos naturais, por parte dos governantes, para a manutenção, tanto do emprego no período de longo prazo, quanto do controle de qualidade do solo e do meio ambiente.

\section{CONCLUSÕES FINAIS:}

Com o advento da "Revolução Industrial" o emprego da tecnologia passou a ser mais intensivo nos sistemas produtivos, isto tornou a tecnologia como sendo um dos fatores de maior importância, dentre os fatores da produção de bens e serviços em uma economia de uma determinada região. 
As alterações no processo produtivo que propicie sua evolução, querem sejam em máquinas e equipamentos, ou ainda mesmo a simples alteração na forma de gestão da produção, e/ou ainda atividades relacionadas que contribuam para a produção de bens e serviços, pode constituir uma alteração tecnológica. Sendo assim, a "inovação tecnológica" pode ocorrer na forma de utilização do processo produtivo, ou ainda em qualquer etapa da produção de novas tecnologias.

Além disto, as alterações tecnológicas nos sistemas produtivos por parte das industrias, deve envolver um planejamento estratégico integrado entre a empresa e o mercado que ela atua, devendo ser observado sua capacidade de financiamento para realizar os investimentos necessários, além da viabilidade econômica e financeira dos projetos de desenvolvimento tecnológico.

Segundo o pensamento formulado por KEYNES (1985) em sua Teoria do Emprego, do Juro e da Moeda, o Estado deverá estimular a atividade econômica para que a economia possa atingir o estágio de Pleno Emprego dos Fatores de Produção; ou seja, são necessários investimentos governamentais em infra-estrutura, para que se possa implantar ou estimular o desenvolvimento tecnológico industrial de uma determinada região.

O que produzir, como produzir, para quem produzir, tornam-se questões chaves que devem fazer parte de todo processo de gestação de projetos tecnológicos e econômicos.

No caso específico do estado do Paraná, apenas uma ação isolada do Governo estadual é insuficiente para atingir o "Desenvolvimento Regional Industrial", torna-se imprescindível uma atuação conjunta das esferas Municipal, Estadual e Federal no tocante a políticas de Desenvolvimento, criando assim um cenário propício para atração de investimentos, e realizando o papel de normalização para a Gestão da Tecnologia.

Portanto, embora SHUMPETER (1954) tenha descrito com muita propriedade que a existência do "Lucro Empresarial" seja um elemento essencial para o desenvolvimento econômico de uma região, caberá ao governo o papel de "Gestor da Tecnologia", a fim de promover não só a geração de empregos e aumento de renda, mas também a manutenção das condições ambientais, sendo estas também essenciais para a "qualidade de vida" de uma população.

O grande desafio das economias em desenvolvimento ao longo do século XXI, será o de possibilitar o uso da tecnologia para satisfazer as necessidades sociais da comunidade local, integrando as relações econômicas e sociais com a exploração não predatória dos recursos naturais, a fim de garantir a qualidade de vida atual e futura da população de uma determinada região; ou seja, promover o que muitos autores chamam de "Desenvolvimento Sustentável" em uma região.

\section{REFERÊNCIAS BIBLIOGRÁFICAS:}

BARBIERI, José Carlos. Produção e Transferência de Tecnologia. São Paulo: Editora Ática, 1990.

BRASIL, Haroldo Vinagre. Gestão financeira das empresas; um modelo dinâmico. Rio de Janeiro: Qualitymark, 1991. 
CLEMENTE, Ademir et al. Projetos Empresariais e Públicos. São Paulo: Editora Atlas, 1998.

DEMINNG W. Edwards - Qualidade: a revolução da administração - Rio de Janeiro: Editora Saraiva, 1990.

DEMINNG W. Edwards - 0 método de Administração - São Paulo: Editora Saraiva, 1989.

FLEURIET, Michel. A dinâmica financeira das empresas brasileiras. Belo Horizonte: Fundação Dom Cabral, 1980.

FIPECAFI. Manual de contabilidade das sociedades por ações. São Paulo: Atlas, 1995.

GARTNER, Ivan Ricardo. Análise de Projetos em Bancos de Desenvolvimento. Florianópolis: Editora da UFSC, 1998.

KEYNES, John Mainardes. A teoria geral do emprego, do juro e da moeda; inflação e deflação. 2 2a . Edição - São Paulo: Nova Cultural, 1985.

MARTINS, Eliseu. Contabilidade de custos. São Paulo: Atlas, 1998.

MATARAZZO, Dante Carmine. Análise Financeira de Balanços - 2ª . Edição. São Paulo: Editora Atlas, 1991.

MEADOWS, D.H. et al. Limites do Crescimento. São Paulo: Perspectiva, 1978.

PORTER, Michael E. Estratégia Competitiva: Técnicas para Análise de Industrias e da Concorrência.Tradução de Elizabeth Maria de Pinto Braga; revisão técnica de Jorge a Garcia Gómez. 5ª edição. Rio de Janeiro: Campus, 1991.

REIS, Dálcio Roberto dos (2000). Contributos para a melhoria da eficiência e da eficácia nas relações de cooperação entre universidades e pequenas e médias empresas industriais brasileiras. Tese de doutoramento em Gestão Industrial. Universidade de Aveiro, Portugal, Departamento de Gestão e Engenharia Industrial. 377p. 03 de maio de 2000.

ROSENBERG N., S. KLINE. An Overview of Innovation, appeared in Landau R. and N. Rosenberg (eds). The Positive Sum Strategy: Harnessing Technology for Economic Growth, Washington D.C.: National Academy Press, 1986.

ROSENBERG N. Exploring the Black Box: Technology and Economics, Cambridge, M.A., Cambridge University Press, 1994.

ROSSETTI, José Pascoal. Introdução à Economia. 17ạ. edição. São Paulo: Atlas, 1997.

SMITH, Adam. A Riqueza das Nações. Coleção os Economistas. São Paulo: Abril Cultural, 1983. 
SHUMPETER, Joseph Alois. A Teoria do Desenvolvimento Econômico. Coleção os Economistas. São Paulo: Abril Cultural, 1982.

VIEIRA SOBRINHO, José Dutra. Matemática financeira. 6. ed. São Paulo: Atlas, 1997.

http://www.pr.gov.br/seit/programas.html

http://www.bndes.gov.br/apresent/pepresi.htm

http://www.brde.com.br 